ISSN 1112-9867

\title{
EFFECTS OF ADIPONECTIN ON MARKERS OF ENDOTHELIAL ACTIVATION AND MARKERS OF INFLAMMATION IN HUMAN CORONARY ARTERY ENDOTHELIAL CELLS
}

\author{
N. A. Rosman ${ }^{1 *}$, G. R. A. Froemming ${ }^{2}$, O. Effat ${ }^{2}, \mathrm{H} \mathrm{Nawawi}^{3}$, and H. J. Singh $^{3}$ \\ ${ }^{1}$ Faculty of Sports Science and Coaching, Universiti Pendidikan Sultan Idris, Tg Malim, \\ Perak, Malaysia \\ ${ }^{2}$ Institute of Medical Molecular Biotechnology, Faculty of Medicine, Universiti Teknologi \\ MARA, Malaysia \\ ${ }^{3}$ Centre for Pathology Diagnostic and Research Laboratories, Faculty of Medicine, Universiti \\ Teknologi MARA, Malaysia
}

Published online: 10 November 2017

\begin{abstract}
This study investigates the effect of adiponectin on endothelial activation and inflammatory marker secretion by human coronary artery endothelial cells (HCEAC) in vitro. Methodology: HCAEC at the seventh passage were divided into two groups and incubated for 24 hours at $37^{\circ} \mathrm{C}$ and $5 \% \mathrm{CO}_{2}$ as follows: Control, and adiponectin-treated $(30 \mu \mathrm{g} / \mathrm{ml}$ adiponectin) groups. Supernatants were analysed for ICAM-1, E-selectin, PAI-1 and IL-6 and COX-2 using ELISA. RT-PCR was used to analyse gene expression of ICAM-1, E-selectin, PAI-, IL-6, COX-2, NFkBp50 and NFkBp65. Data were analysed using independent t-test. Results: ICAM-1 and E-selectin level was significantly higher in leptin-adiponectin-treated groups $(\mathrm{P}<0.01)$. Endothelial activation marker protein level have no significant difference in adiponectin group when compared to control group.
\end{abstract}

Author Correspondence, e-mail: nooraiwa@fsskj.upsi.edu.my

doi: http://dx.doi.org/10.4314/jfas.v9i6s.81 
mRNA expression showed significant increase in adiponectin group as compared to control. PAI-1 and COX-2 showed no significant increase in the level of protein in adiponectin group but IL-6 showed significant increased in the protein level $(\mathrm{P}<0.001)$ while mRNA expression of PAI-1 $(\mathrm{P}<0.05), \mathrm{COX}-2(\mathrm{P}<0.01)$ and IL-6 $(\mathrm{P}<0.001)$ showed significant increase in treated group as compared to control. mRNA expression also showed significant increase in both the NFkBp50 and NFkBp65 signalling pathway.

Conclusion: Adiponectin increases the secretion of IL-6 from HCEAC. This adipokines might have a significant role in the inflammatory and pro-atherogenic state of obesity.

Keywords: HCAEC, Adiponectin, ICAM-1, E-selectin, IL-6, PAI-1, COX-2, NFkB.

\section{INTRODUCTION}

Adipose tissue has been shown to secrete bioactive substances (adipokines) that influence endothelial function [1-3]. Although the precise link between cardiovascular morbidity and adipokines remains unclear, a low inflammatory state with generalized endothelial activation is believed to underlie the risk for diseases like hypertension, atherosclerosis and ischaemic heart disease. Much, however, remains to be examined on the link between adipokines and cardiovascular diseases. Adipose tissue secretes a variety of bioactive molecules that might directly contribute to the low inflammatory state and development of cardiovascular diseases like atherosclerosis [4]. One of the earliest events in atherosclerosis is the recruitment and binding of circulating leukocytes to the vascular endothelium. Then, further movement of leukocytes into the sub-endothelial spaces during development of atherosclerosis is facilitated through cellular adhesion molecules Atherosclerosis Risk In Communities (ARIC) study found a significant link between circulating vascular cell adhesion molecule-1 (VCAM-1), endothelial-leukocyte adhesion molecule-1 (E-selectin), intercellular adhesion molecule-1 (ICAM-1) and the degree of atherosclerosis as identified by B-mode ultrasound $[5,6]$.

Adiponectin levels are reduced in obesity [1]. Adiponectin, a $30 \mathrm{kDa}$ plasma protein secreted by adipose tissue correlates negatively with percentage of body fat, waist to hip ratio and intra-abdominal fat [7-9]. Plasma adiponectin concentrations are lower in patients with clinical symptoms of coronary artery disease than in age- and BMI-adjusted control subjects $[10,11]$. Adiponectin has been reported to have an anti-atherogenic effect, as in cultured 
cells human recombinant adiponectin was found to suppress the endothelial expression of adhesion molecules, the proliferation of smooth muscle cells and the transformation of macrophage to foam cells [10].

Many different signalling pathways are involved in the progression of inflammatory response. This inflammatory state has been proposed to be a contributing factor between obesity and cardiovascular diseases [12]. NFkB has been indicated to influence numerous cardiovascular diseases [12] and NFkB transcription factors are one of the distinguished components that regulate genes engaged in the inflammatory process [13]. Endothelial cells activation and expression are controlled by NFkB signalling [14].

Whilst numerous reports exist on the effect of leptin and adiponectin on endothelial function little is known about the interaction between leptin and adiponectin together on endothelial cell function. It is unclear if adiponectin antagonises the actions of leptin on the endothelium. This study therefore investigates the effect of leptin and adiponectin on ICAM-1, E-selectin, PAI-1 and IL-6 and COX-2 secretion by human coronary artery endothelial cells (HCAEC) in vitro.

\section{METHODOLOGY}

Human coronary artery endothelial cells (HCAEC) (Lonza, USA), at the seventh passage, were cultured in $12 \mathrm{~T} 75$ flasks at $37^{\circ} \mathrm{C}$ and $5 \% \mathrm{CO}_{2}$ in endothelial growth media-2 (EGM-2, Lonza, USA) supplemented with 5\% FBS, $0.04 \%$ hydrocortisone, $0.4 \%$ hFGF-B, $0.1 \%$ VEGF, $0.1 \%$ R3-IGF-1, 0.1\% ascorbic acid, 0.1\% hEGF and 0.1\% GA-1000) with $>90 \%$ purity (by SDS PAGE) until $80 \%$ confluent. The flasks with the cultured cells were then divided into two groups with 3 flasks in each group and incubated for 24 hours as follows: Control and adiponectin-treated (30 $\mu \mathrm{g} / \mathrm{ml}$ Human Recombinant Adiponectin - Biovision) groups. After 24 hours of incubation the cells were detached from the flasks using accutase and the cell suspension was centrifuged for 5 minutes at $220 \mathrm{~g}$. The supernatants were analysed for ICAM-1, E-selectin, PAI-1 and IL-6 and COX-2 using commercially available ELISA kits (eBioscience) whilst the cell lysate was used for the extraction of mRNA and expression studies. The concentrations of these in the supernatants were standardised for the cell counts and expressed as percentage of the controls. 
Real time RNA analyses were performed to determine the effect of leptin and adiponectin treatment on ICAM-1, E-selectin, IL-6 and COX-2 transcription and also NFkBp50 and NFkBp65. Total RNA was extracted from the treated cells using AllPrep RNA/Protein kit (Qiagen, Germany). Reverse transcription was performed from $30 \mathrm{ng}$ of RNA using iScript $^{\mathrm{TM}}$ cDNA Synthesis Kit (BIO-RAD, CA). The cDNA templates $(1 \mu \mathrm{l})$ were added per $10 \mu 1$ reaction with sequence specific primers of ICAM-1, E-selectin, IL-6 transcription in treated cells. All target gene primers were purchased from AIT Biotech (Singapore). For the analysis of ICAM-1, forward primer 5'-ATGCCCAGACATCTGTGTCC-3' and reverse 5'GGGGTCTCTATGCCCAACAA-3' were used. For the E-selectin, forward primer 5'-CAGCAAAGGTACACACACCTG-3' and reverse 5'-CAGACCCACACATTGTTGACTT-3' were used. For IL-6, the forward primer 5' ACTCACCTCTTCAGAACGAATTG-3, and the reverse primer 5' CCATCTTTGGAAGGTTCAGGTTG-3' were used. The forward primer for PAI-1 was 5'CCTGGGCACTTACAGGAAGG-3' while reverse primer was 5'GGTCCGATTCGTCGTCAAATAAC-3'. For COX-2, the forward and reverse primers were 5'- CCAGTAtAaGtGCGATtGTACCC-3' and 5'- TCAAAAATTCCGGTGTTGAGCA-3' respectively. The forward primer for NFkBp50 was 5'-AACCTGCAGCAGACTCCACT-3' and reverse 5'-ACACCAGGTCAGGATTTTGC-3' while forward primer for NFkBp65 was 5'-TCAATGGCTACACAGGACCA-3', and reverse was 5'-CACTCTCACCTGGAAGCAGA-3', For GAPDH 5'-CTGGGCTACACTGAGCACC-3' and 5'-AAGTGGTCGTTGAGGGCAATG-3' were used as forward and reverse primers respectively and for HPRT-1 the forward and reverse primers were 5'-CCTGGCGTCGTGATtAGTGAT-3' and 5'- AGACGTTCAGTCCTGTCCATAA-3' respectively. These were used as reference genes. Assays were carried out in triplicate using CFX96 version 2.1 (BIO-RAD, CA). Amplification curves for ICAM-1; E-selectin and IL-6, PAI-1 and COX-2 were produced with an initial denaturing step at $95^{\circ} \mathrm{C}$ for $30 \mathrm{sec}$, followed by 40 cycles at $95^{\circ} \mathrm{C}$ for $5 \mathrm{sec}$ and $60^{\circ} \mathrm{C}$ for $10 \mathrm{~s}$. Amplification curves for NFkB were generated with an initial step of denaturing at $3 \mathrm{~min}$, followed by 50 cycles at $95^{\circ} \mathrm{C}$ for $10 \mathrm{~s}$ and $60^{\circ} \mathrm{C}$ for 45 s. Reactions were normalized to copies of GAPDH and HPRT-mRNA within the same sample using $-\Delta \Delta \mathrm{CT}$ method. Results are expressed as fold increases compared to control. 
Data are presented as mean \pm SEM. Data were analysed using independent sample t-test, with level of significance set at $p<0.05$.

Table 1. Primer Sequence for Housekeeping Gene, Markers of Inflammation and Endothelial Activation

\begin{tabular}{|c|c|c|}
\hline \multicolumn{3}{|c|}{ Housekeeping } \\
\hline \multirow[t]{2}{*}{ GAPDH } & $\mathrm{F}$ & 5'-CTGGGCTACACTGAGCACC-3' \\
\hline & $\mathrm{R}$ & 5'-AAGTGGTCGTTGAGGGCAATG-3' \\
\hline \multirow[t]{2}{*}{ HPRT-1 } & $\mathrm{F}$ & 5'-CCTGGCGTCGTGATTAGTGAT-3' \\
\hline & $\mathrm{R}$ & 5'-AGACGTTCAGTCCTGTCCATAA-3' \\
\hline \multicolumn{3}{|c|}{ Markers of Inflammation } \\
\hline \multirow[t]{2}{*}{ IL-6 } & $\mathrm{F}$ & 5'-ACTCACCTCTTCAGAACGAATTG-3' \\
\hline & $\mathrm{R}$ & 5'-CCATCTTTGGAAGGTTCAGGTTG-3' \\
\hline \multirow[t]{2}{*}{ PAI-1 } & $\mathrm{F}$ & 5'-CCTGGGCACTTACAGGAAGG-3' \\
\hline & $\mathrm{R}$ & 5'-GGTCCGATTCGTCGTCAAATAAC-3' \\
\hline \multirow[t]{2}{*}{$\mathrm{COX}-2$} & $\mathrm{~F}$ & 5'-CCAGTATAAGTGCGATTGTACCC-3' \\
\hline & $\mathrm{R}$ & 5'-TCAAAAATTCCGGTGTTGAGCA-3' \\
\hline \multirow[t]{2}{*}{ NFkBp50 } & $\mathrm{F}$ & 5'-AACCTGCAGCAGACTCCACT-3' \\
\hline & $\mathrm{R}$ & 5'-ACACCAGGTCAGGATTTTGC-3' \\
\hline \multirow[t]{2}{*}{ NFkBp65 } & $\mathrm{F}$ & 5'-TCAATGGCTACACAGGACCA-3' \\
\hline & $\mathrm{R}$ & 5'-CACTCTCACCTGGAAGCAGA-3' \\
\hline \multicolumn{3}{|c|}{ Markers of Endothelial Activation } \\
\hline \multirow[t]{2}{*}{ ICAM-1 } & $\mathrm{F}$ & 5'-ATGCCCAGACATCTGTGTCC-3' \\
\hline & $\mathrm{R}$ & 5'-GGGGTCTCTATGCCCAACAA-3' \\
\hline \multirow[t]{2}{*}{ E-selectin } & $\mathrm{F}$ & 5'-CAGCAAAGGTACACACACCTG-3' \\
\hline & $\mathrm{R}$ & 5'-CAGACCCACACATTGTTGACTT-3' \\
\hline
\end{tabular}




\section{RESULTS}

\subsection{Endothelial Activation Marker}

Table 2. Soluble ICAM-1 and E-selectin concentrations in the supernatants expressed as

\begin{tabular}{ccc}
\multicolumn{3}{c}{ percentage of control } \\
\hline & $\mathrm{C}$ & $\mathrm{A}$ \\
\hline ICAM-1 & $100 \pm 4.19$ & $108.02 \pm 8.90$ \\
\hline E-selectin & $100 \pm 4.35$ & $115.66 \pm 9.70$ \\
\hline
\end{tabular}

Table 2 presents ICAM-1 protein concentrations in the supernatants after 24 hours of incubation with and without adiponectin, expressed as percentage of the control. ICAM-1 protein levels and soluble E-selectin protein levels in the supernatant have no effects to adiponectin.

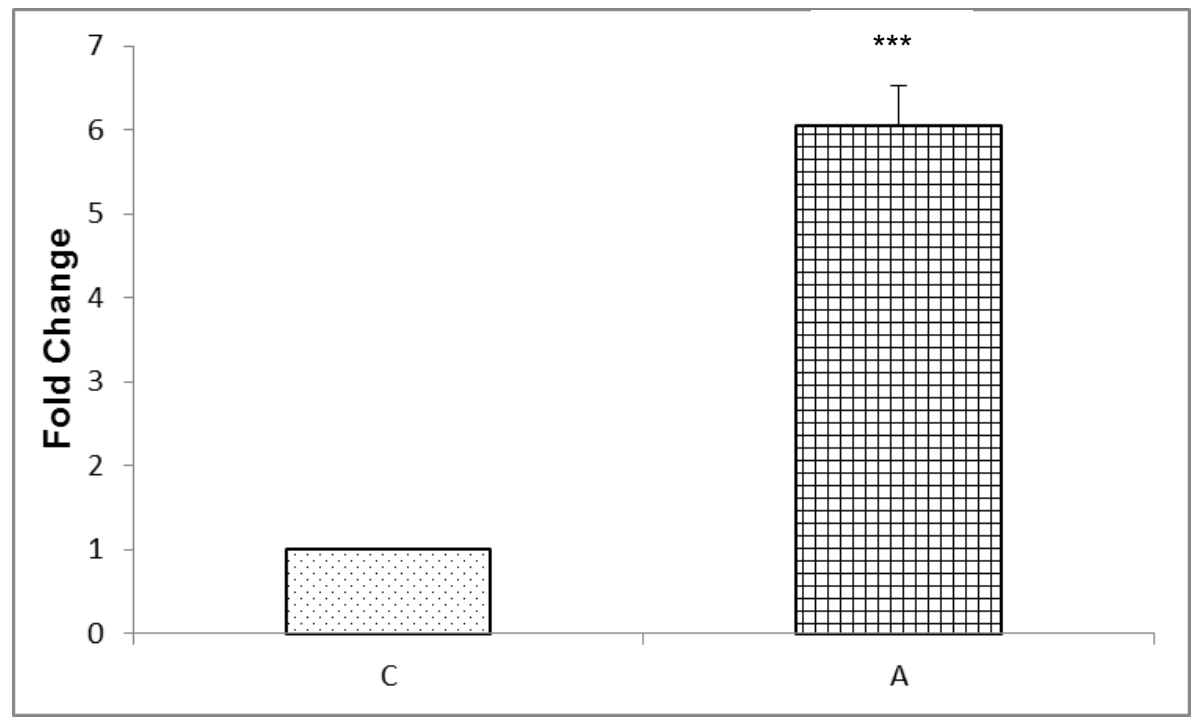

${ }^{* * *} \mathrm{P}<0.001$; compared to control

Figure 1: ICAM-1 mRNA expression (Fold increase)

The ICAM-1 mRNA expression in adiponectin treated group was significantly higher when compared to that in the control, $(\mathrm{P}<0.001$; Figure 1$)$. 


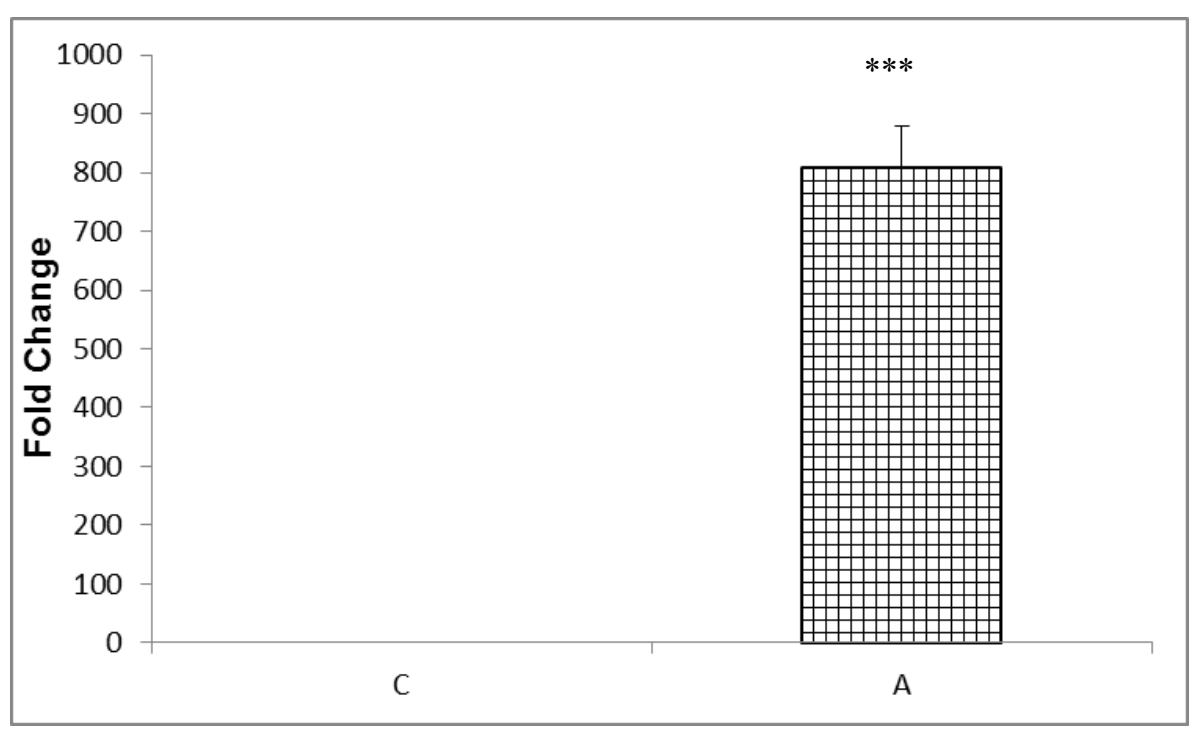

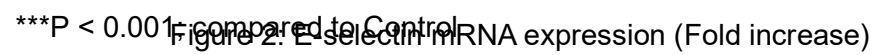

The E-selectin mRNA expression in adiponectin treated group was significantly higher than that in the control groups $(\mathrm{P}<0.001$; Figure 2$)$.

\subsection{Inflammation Marker}

Table 3. Soluble PAI-1, IL-6 and COX-2 protein concentration in supernatants expressed as

\begin{tabular}{ccc}
\multicolumn{3}{c}{ percentage of control } \\
\hline & $\mathrm{C}$ & $\mathrm{A}$ \\
\hline PAI-1 & $100 \pm 23.20$ & $117.64 \pm 19.90$ \\
\hline IL-6 & $100 \pm 23.20$ & $761.95 \pm 94.00^{* * *}$ \\
\hline COX-2 & $100 \pm 28.70$ & $193.93 \pm 36.34$ \\
\hline
\end{tabular}

$* * * \mathrm{P}<0.001 ;$ compared to Control

PAI-1 and COX-2 protein levels in the supernatant of adiponectin treated groups have no significance difference than those of control. On the other hand, IL-6 was found to be significantly higher in the treated group $(\mathrm{P}<0.001$; Table 2$)$. 


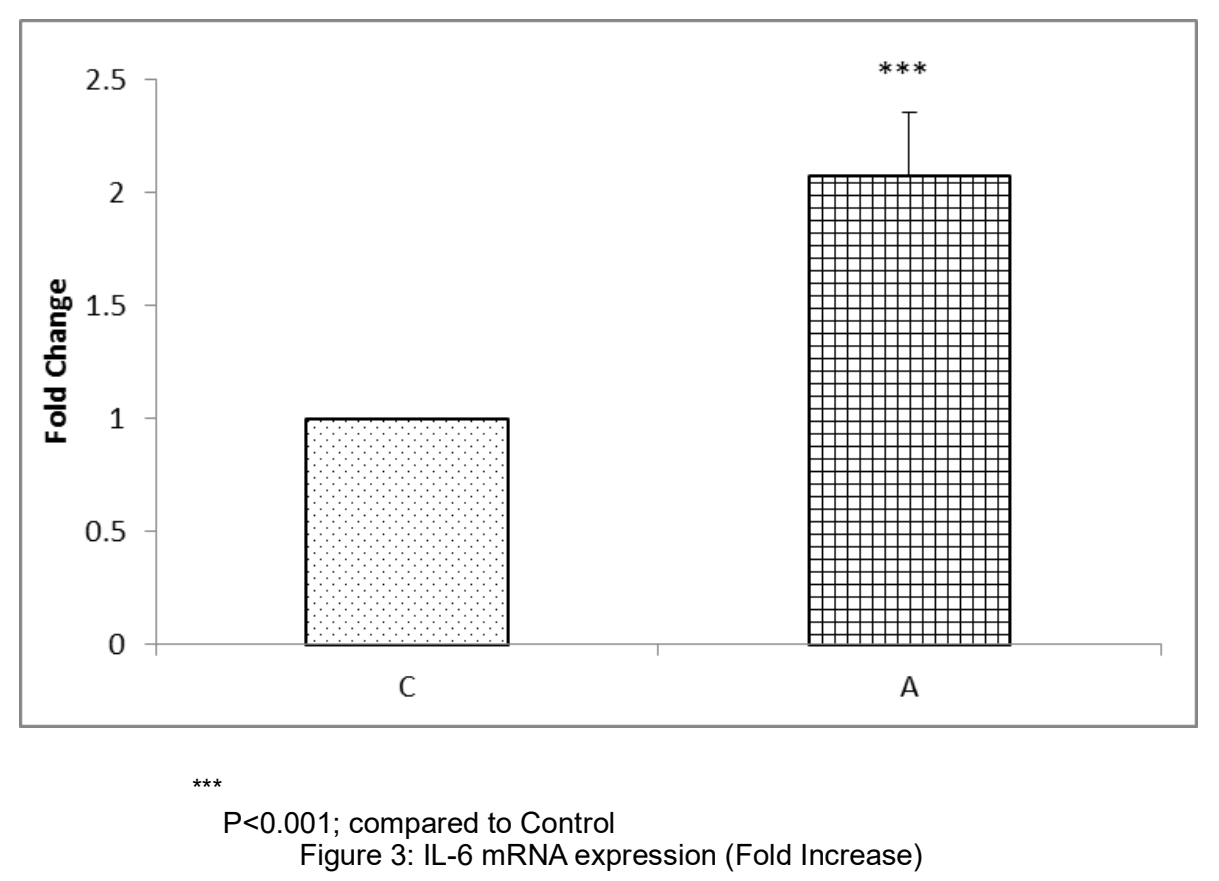

The mRNA expression of IL-6 expression in the adiponectin group was significantly higher than that in the control group $(\mathrm{P}<0.001$; Figure 3$)$.

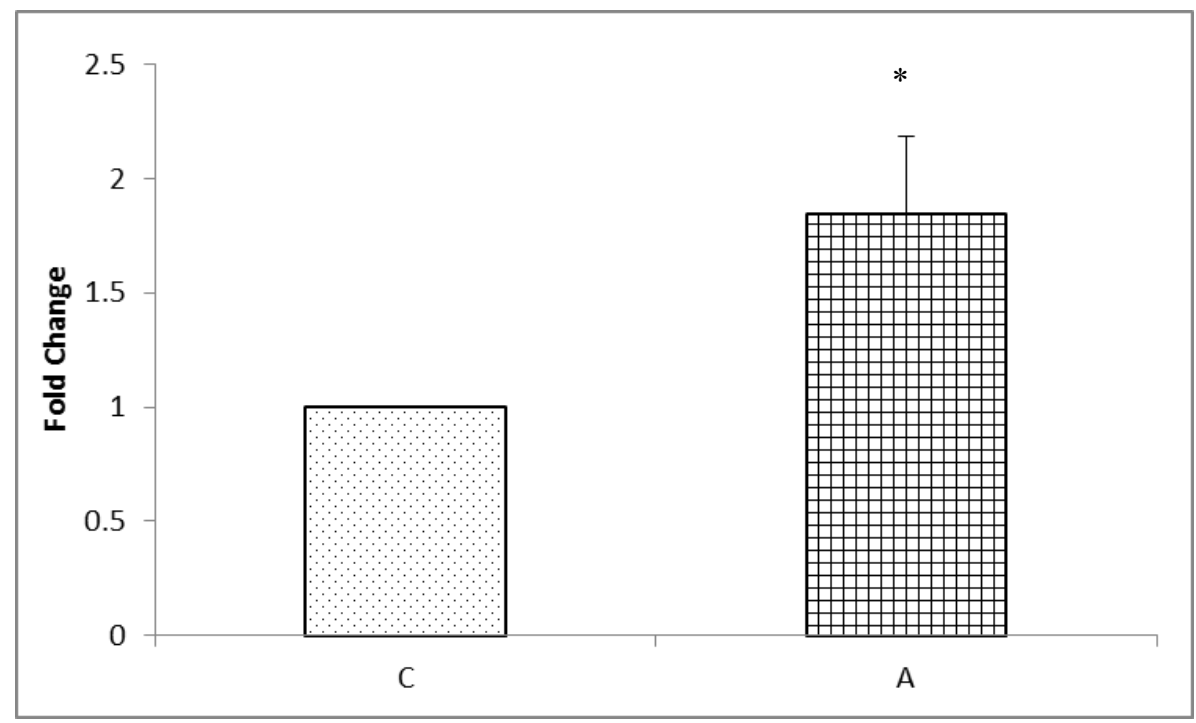

$\mathrm{P}<0.05$; compared to Control

Fig.4: PAI-1 mRNA expression (Fold Increase) 
PAI-1 mRNA expression in the adiponectin group was found to be significantly higher than that in the control group $(\mathrm{P}<0.05$; Figure 4$)$.

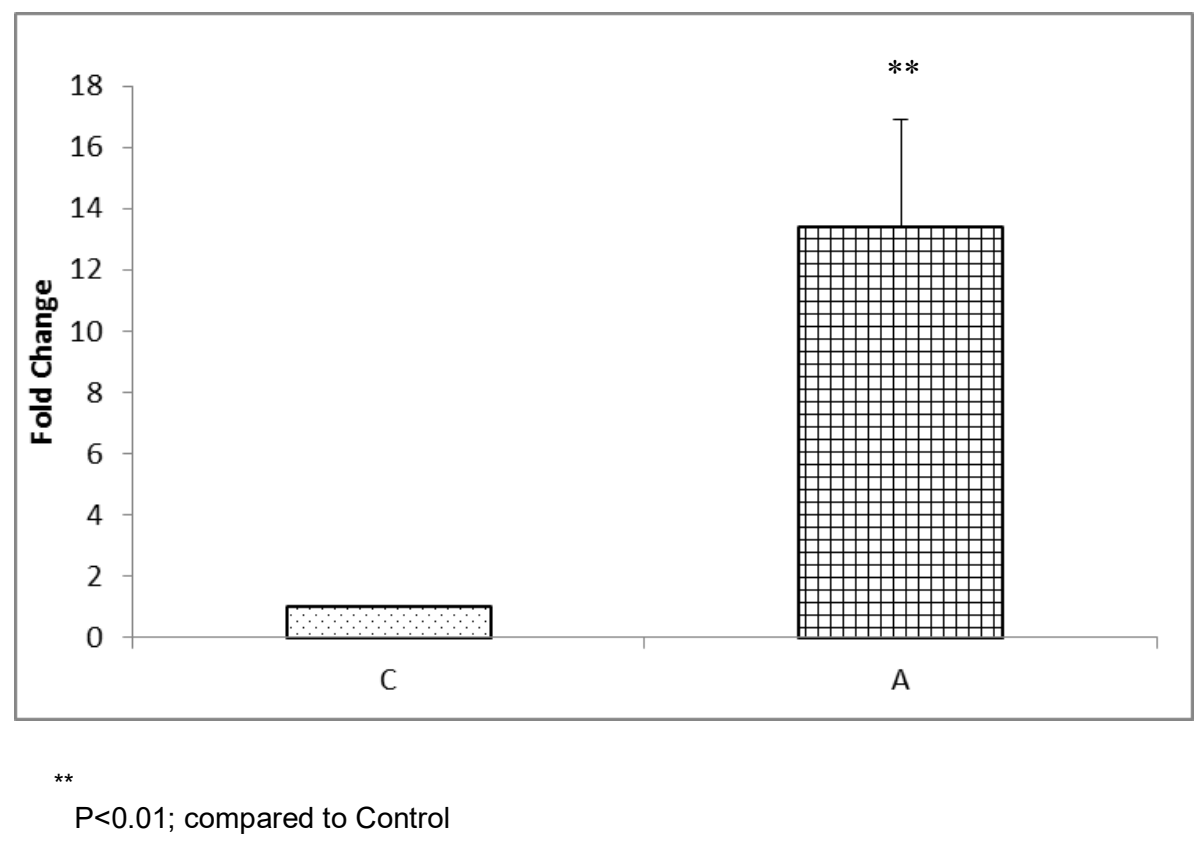

Figure 5: COX-2 mRNA expression (Fold Increase)

COX-2 mRNA expression in the adiponectin group was significantly higher than that in the control group $(\mathrm{P}<0.01$; Figure 5). 


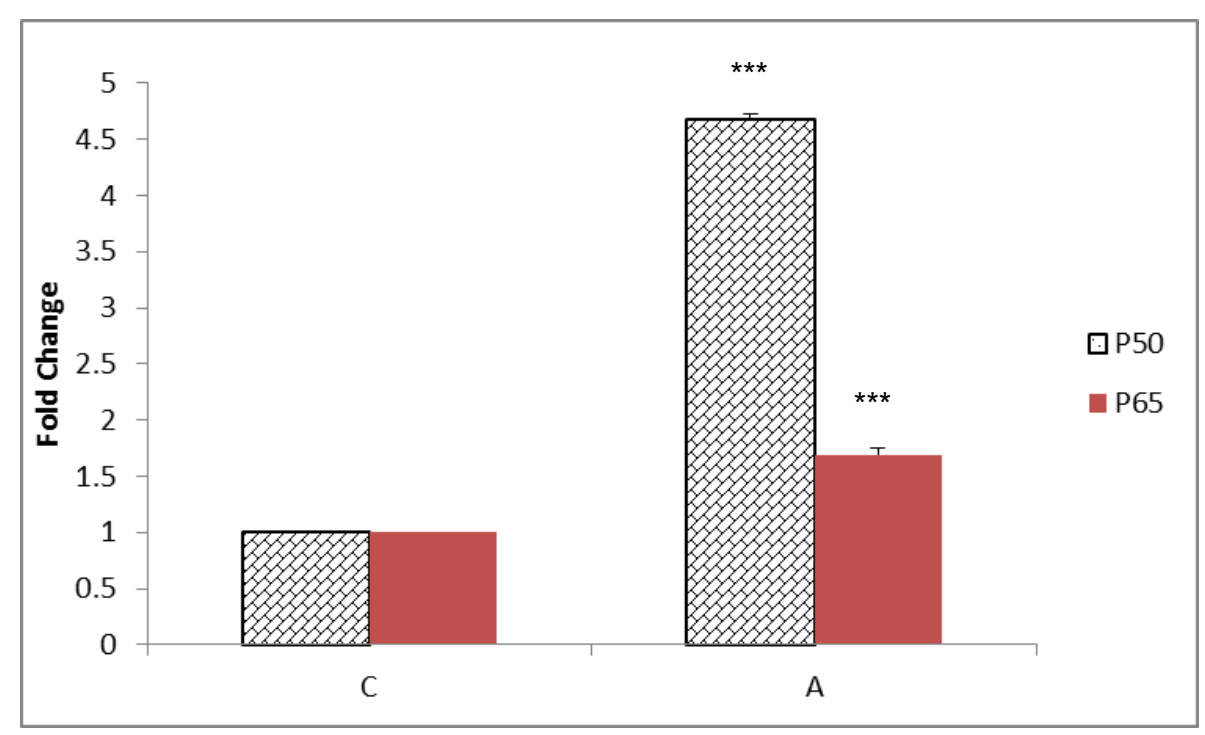

${ }^{* * *} \mathrm{P}<0.001$; compared to Control

Figure 6: NFkBp50 and NFkBp65 mRNA expression (Fold increase)

Both NFkBp50 and NFkBp65 expression were found to be significantly higher in adiponectin treated group $(\mathrm{P}<0.001)$, when compared to that in the controls.

\section{DISCUSSION}

The major findings of this study are that (i) adiponectin significantly increased the levels of IL-6 protein secretion in cultured HCAEC, and (ii) adiponectin independently up-regulated the expression of ICAM-1, E-selectin, PAI-1, IL-6, COX-2, NFkBp50 and NFkBp65 mRNA in human coronary artery endothelial cells.

Endothelial dysfunction is characterized with a few changes that the endothelium undertakes during the proses of atherogenesis. These includes i) damage to the anticoagulant properties of the endothelium, ii) increased expression of the cellular adhesion molecules and iii) loss of bioavailability of vasodilatory endothelial nitric oxide. Obesity is characterized as chronic low-grade inflammatory, and adiponectin level is decreased in obesity indicating dysregulation of adiponectin could be applicable to obesity-linked disorder. In the early phases of atherosclerosis endothelial cell activation by numerous inflammatory stimuli will results in the synthesis of adhesion molecules [15]. Adiponectin is an adipocyte-specific plasma protein which regulates inflammatory stimuli in endothelial cells endogenously [11]. The effect of 
adiponectin on endothelial cells in culture has been reported before, in which adiponectin (50 $\mathrm{ug} / / \mathrm{mL}$ ) treatment alone did not indicate any significant modifications in the surface expression of ICAM-1 and E-selectin in human aortic endothelial cells (HAEC) [11]. The mRNA expression of adhesion molecules however was done by using Northern Blot analysis and no significant difference was found in HAECs that was 18 hours pre-treated with adiponectin.

Plasminogen activator inhibitor 1 (PAI-1) is the major inhibitor of plasminogen in vivo and increased PAI-1 in plasma will interfere the mechanism of fibrin clearance hence encourage thrombosis [16]. PAI-1 is noticeably elevated in obesity and associated with increased risk of certain diseases such as atherosclerosis, myocardial infarction and hypertension. In this study we demonstrated that the soluble protein concentration of PAI-1 has no significance difference between untreated HCAEC as compared with adiponectin treated cells. However, the mRNA expression of PAI-1 was significantly increased by 1.8 fold in the treated group. It was observed that significant improvements in PAI-1 plasma level were evident in patients after 1 year of weight loss therapy in both metabolic syndrome and non-metabolic syndrome groups. It was also evident that the level of adiponectin, which was identified as an anti-inflammatory cytokine did not increased significantly post-therapy in the metabolic syndrome group [17].

IL-6 was defined as proinflammatory cytokine and synthesized by a range of tissues such as adipocytes, stimulated leucocytes and also endothelial cells. Several studies demonstrated that the level of IL- 6 in the plasma is notably elevated in condition of insulin resistance and obesity [18-20]. In this study both the soluble protein concentration of IL-6 and gene expression in cultured HCAEC showed significant increase in the adiponectin treated group as compared to non-treated cells with the mRNA expression showed 2-fold increased.

It was stated that adiponectin protects the heart from numerous damages [21]. Myocardial ischemia-reperfusion injury was prevented through AMPK- and COX-2-dependent mechanisms [22]. This study showed marked increase in the mRNA expression of COX-2 by 13-fold even though the translation of protein does not show significant difference. Study showed that adiponectin increases COX-2 expression in primary neonatal rat ventricular cardiac myocytes treated with $30 \mathrm{ug} / \mathrm{mL}$ adiponectin and incubated for 18 hours [23].

$\mathrm{NFkB}$ has long been acknowledged as a pro-inflammatory signaling pathway, in which the activation of NFkB is through the commencement of pro-inflammatory cytokines, chemokines 
and adhesion molecules [24]. Activation of NFkB normally will cause the up-regulation of anti-apoptotic genes thus enabling the cells to bear stresses elicited during the progression of inflammation. NFkB also stimulate cytokine as well as adhesion molecules which result in the leucocyte engagement to the inflamed area. In this study, NFkBp50 was found to be significantly up-regulated in adiponectin treated $(\mathrm{P}<0.001)$ group as compared to control. Meanwhile, NFkBp65 significantly increased in the mRNA expression in adiponectin treatment compared to control $(\mathrm{P}<0.001)$ group. Homodimers of the p50 NFkB subunit with deficient of transactivation domains have been indicated to inhibit expression of NFkB target genes and inhibit inflammation [25]. These findings may suggest comprehensive role of well-labelled pro- and anti-atherosclerotic property of adiponectin.

\section{CONCLUSION}

Adiponectin increases the expression of ICAM-1, E-selectin, IL-6, PAI-1, COX-2, NFkBp50 and also NFkBp65 from HCEAC. This adipokines might have a significant role in the inflammatory and pro-atherogenic state of obesity.

\section{ACKNOWLEDGEMENT}

This work was supported by grants from the Long Term Research Grant Scheme (LRGS) Ministry of Higher Education, 600-RMI/LRGS 3/5(2/2011).

\section{REFERENCES}

[1] Ntaios, G., et al., Adipokines as mediators of endothelial function and atherosclerosis. Atherosclerosis, 2013. 227(2): p. 216-221.

[2] Knudson, J.D., et al., Leptin receptors are expressed in coronary arteries, and hyperleptinemia causes significant coronary endothelial dysfunction. American Journal of Physiology-Heart and Circulatory Physiology, 2005. 289(1): p. H48-H56.

[3] Santos-Alvarez, J., R. Goberna, and V. Sánchez-Margalet, Human leptin stimulates proliferation and activation of human circulating monocytes. Cellular immunology, 1999. 194(1): p. 6-11. 
[4] Katagiri, H., T. Yamada, and Y. Oka, Adiposity and cardiovascular disorders. Circulation Research, 2007. 101(1): p. 27-39.

[5] Investigators, A., The Atherosclerosis Risk in Communities (ARIC) study: design and objectives. American journal of epidemiology, 1989. 129(4): p. 687-702.

[6] Hwang, S.-J., et al., Circulating adhesion molecules VCAM-1, ICAM-1, and E-selectin in carotid atherosclerosis and incident coronary heart disease cases. Circulation, 1997. 96(12): p. 4219-4225.

[7] Goldstein, B.J. and R. Scalia, Adiponectin: a novel adipokine linking adipocytes and vascular function. The Journal of Clinical Endocrinology \& Metabolism, 2004. 89(6): p. 2563-2568.

[8] Cnop, M., et al., Relationship of adiponectin to body fat distribution, insulin sensitivity and plasma lipoproteins: evidence for independent roles of age and sex. Diabetologia, 2003. 46(4): p. 459-469.

[9] Weyer, C., et al., Hypoadiponectinemia in obesity and type 2 diabetes: close association with insulin resistance and hyperinsulinemia. The Journal of Clinical Endocrinology \& Metabolism, 2001. 86(5): p. 1930-1935.

[10]Kumada, M., et al., Association of hypoadiponectinemia with coronary artery disease in men. Arteriosclerosis, thrombosis, and vascular biology, 2003. 23(1): p. 85-89.

[11]Ouchi, N., et al., Novel modulator for endothelial adhesion molecules. Circulation, 1999. 100(25): p. 2473-2476.

[12]Taube, A., et al., Inflammation and metabolic dysfunction: links to cardiovascular diseases. American Journal of Physiology-Heart and Circulatory Physiology, 2012. 302(11): p. H2148-H2165.

[13]Bonizzi, G. and M. Karin, The two NF- $\kappa B$ activation pathways and their role in innate and adaptive immunity. Trends in immunology, 2004. 25(6): p. 280-288.

[14]Monaco, C., et al., Canonical pathway of nuclear factor $\kappa \mathrm{B}$ activation selectively regulates proinflammatory and prothrombotic responses in human atherosclerosis. Proceedings of the National Academy of Sciences of the United States of America, 2004. 101(15): p. 5634-5639. 
[15]Ross, R., The pathogenesis of atherosclerosis: a perspective for the 1990s. Nature, 1993. 362(6423): p. 801-809.

[16]Loskutoff, D.J. and F. Samad, The adipocyte and hemostatic balance in obesity. Arteriosclerosis, thrombosis, and vascular biology, 1998. 18(1): p. 1-6.

[17]Corgosinho, F.C., et al., The role of PAI-1 and adiponectin on the inflammatory state and energy balance in obese adolescents with metabolic syndrome. Inflammation, 2012. 35(3): p. 944-951.

[18]Pickup, J., et al., NIDDM as a disease of the innate immune system: association of acute-phase reactants and interleukin-6 with metabolic syndrome X. Diabetologia, 1997. 40(11): p. 1286-1292.

[19] Vozarova, B., et al., Circulating interleukin-6 in relation to adiposity, insulin action, and insulin secretion. Obesity, 2001. 9(7): p. 414-417.

[20]Pradhan, A.D., et al., C-reactive protein, interleukin 6, and risk of developing type 2 diabetes mellitus. Jama, 2001. 286(3): p. 327-334.

[21 Ohashi, K., et al., Adiponectin replenishment ameliorates obesity-related hypertension. Hypertension, 2006. 47(6): p. 1108-1116.

[22] Shibata, R., et al., Adiponectin protects against myocardial ischemia-reperfusion injury through AMPK-and COX-2-dependent mechanisms. Nature medicine, 2005. 11(10): p. 1096-1103.

[23]Ikeda, Y., et al., Cyclooxygenase-2 induction by adiponectin is regulated by a sphingosine kinase-1 dependent mechanism in cardiac myocytes. FEBS letters, 2008. 582(7): p. $1147-1150$.

[24]Lawrence, T., The nuclear factor NF-кB pathway in inflammation. Cold Spring Harbor perspectives in biology, 2009. 1(6): p. a001651.

[25]Bohuslav, J., et al., Regulation of an essential innate immune response by the p50 subunit of NF-kappaB. Journal of Clinical Investigation, 1998. 102(9): p. 1645.

How to cite this article:

Rosman N. A., Froemming G. R. A., Effat O., Nawawi H. and Singh H. J. Effects of Adiponectin on Markers of Endothelial Activation and Markers of Inflammation in Human Coronary Artery Endothelial Cells. J. Fundam. Appl. Sci., 2017, 9(6S), 1102-1115. 